\title{
Avaliação da Decomposição de Plantas Aquáticas no Solo ATRAVÉS DA LIBERAÇÃo DE $\mathrm{CO}_{2}{ }^{1}$
}

\author{
Evaluation of Aquatic Plant Decomposition on Soil through $\mathrm{CO}_{2}$ Release \\ CORREA, M.R. ${ }^{2}$, VELINI, E.D. ${ }^{3}$, ARRUDA, D.P. ${ }^{4}$, ALVES, E. ${ }^{5}$ e SILVA, JRM. ${ }^{6}$
}

\begin{abstract}
RESUMO - O objetivo deste trabalho foi avaliar a decomposição de três espécies de plantas aquáticas imersas, incorporadas ao solo, provenientes do controle mecânico, em reservatórios de usinas hidrelétricas. O estudo foi realizado em casa de vegetação, localizada no Núcleo de Pesquisas Avançadas em Matologia (NUPAM) da FCA/Unesp-Botucatu. A avaliação foi conduzida em vasos contendo $14 \mathrm{~kg}$ de solo, com três incorporações de 50 e 100 t MF de plantas ha ${ }^{-1}$, sob duas condições de solo: seco e úmido. Com a simulação de descarte da biomassa coletada e incorporada ao solo, pôde-se conhecer, através da liberação de $\mathrm{CO}_{2}$, a degradação de três espécies de macrófitas aquáticas submersas. Para quantificação do $\mathrm{CO}_{2}$ liberado, em cada vaso foi acondicionado um frasco com solução de $\mathrm{NaOH}$, sendo, logo após, lacrados e incubados por 24 horas; em seguida, foram titulados com HCl. Para ajuste e interpolação dos dados, estes foram analisados seguindo modelo de Mitscherlich, com algumas modificações. As liberações acumuladas em solo úmido foram de 1.294 e $1.582 \mathrm{~kg} \mathrm{CO} \mathrm{ha}^{-1}$, sendo 6,2 e 5,6 vezes superiores ao ocorrido em solo seco, para 50 e 100 t MF ha ${ }^{-1}$, respectivamente, observando-se que cerca de $55 \%$ da liberação de $\mathrm{CO}_{2}$ ocorreu nos primeiros 30 dias. Pode-se concluir que o solo seco é a melhor condição para descarte e incorporação da biomassa, porém deverá existir um sistema de irrigação para que o processo de degradação da biomassa incorporada seja acelerado.
\end{abstract}

Palavras-chave: controle mecânico, descarte, macrófitas aquáticas.

\begin{abstract}
The purpose of this study was to evaluate decomposition due to mechanical control of three submerged aquatic weed species incorporated into soil at hydroelectric reservoirs. The study was carried out in a greenhouse at the Weed Science Center (NUPAM), FCA/UNESP-Botucatu. Evaluation was performed in vases containing $14 \mathrm{~kg}$ of soil, with three 50 and $100 \mathrm{t}$ plant fresh matter ha $\mathrm{a}^{-1}$ incorporations, under two soil conditions: dry and wet. By simulating the biomass harvested and incorporated into soil, degradation of the three aquatic macrophyte weed species could be verified through released $\mathrm{CO}_{2}$. To quantify released $\mathrm{CO}_{2}$, a flask with NaOH solution was placed into each vase, sealed and incubated for 24 hours, followed by HCl titration. For data adjustment and interpolation, Mitscherlich model modified was used. $\mathrm{CO}_{2}$ released into wet soil was 1,294 and $1,582 \mathrm{~kg} \mathrm{ha}^{-1}$, being 6.2 and 5.6 times than that released into dry soil, for 50 and 100 t FM ha $\mathrm{Fa}^{-1}$, respectively. It was observed that about $55 \%$ of the released $\mathrm{CO}_{2}$ occurred at day 30. It can be concluded that dry soil is the best condition for biomass discard and incorporation. However, degradation is accelerated under irrigation.
\end{abstract}

Key words: mechanical control, discard, aquatic macrophytes.

1 Recebido para publicação em 17.11.2004 e na forma revisada em 5.4.2005.

2 Eng.-Agr., M.S., Programa de pós-graduação em Agricultura, Departamento de Produção Vegetal/Agricultura, FCA/UNESP, Caixa Postal 237, 18603-970 Botucatu-SP, <mrcorrea@fca.unesp.br>; ${ }^{3}$ Professor Dr., Dep. de Produção Vegetal/Agricultura, FCA/UNESP, Botucatu-SP; ${ }^{4}$ Químico, Dep. de Produção Vegetal/Agricultura, FCA/UNESP, Botucatu-SP; ${ }^{5}$ Eng.-Agr., D.S., Dep. de Produção Vegetal/Agricultura, FCA/UNESP, Botucatu-SP. ${ }^{6}$ Graduando em Tecnologia em Gestão de Sistema de Informação, Faculdade Marechal Rondon - FMR, 18650-000 São Manuel-SP. 


\section{INTRODUÇÃO}

No Brasil, devido à extensa rede hidrográfica, existe um elevado número de reservatórios, importantes para o fornecimento de água, que dão suporte aos sistemas de produção, sejam agrícolas ou industriais, navegação, recreação, pesca, consumo humano e geração de energia (Velini, 2000).

A construção de barragens, transformando rios em grandes reservatórios, associada ao carregamento de nutrientes para seu leito, pelo despejo doméstico e industrial, tem levado a uma condição de desequilíbrio do sistema hídrico, que pode ser caracterizado pela grande disponibilidade de nutrientes (Velini, 2000; Braga, 2002), fato este que aumenta a produtividade biológica e ocasiona problemas em decorrência do excessivo desenvolvimento de algas e vegetação aquática (Thomaz e Bini, 1998).

Conforme relatos de Asaeda et al. (2000) e Miyazaki \& Pitelli (2003), as macrófitas aquáticas são importantes componentes de rios e reservatórios, constituindo fontes de oxigênio, alimento e abrigo para a vida aquática. No entanto, a vegetação aquática passa a ser encarada como daninha quando seu crescimento ocorre acentuadamente, em decorrência da eutrofização do meio, causando problemas para os ecossistemas. A partir desse momento, a necessidade de aplicação de métodos de controle ou manejo adequado torna-se indispensável.

Alguns métodos de controle utilizados no país podem ser citados. O controle biológico testado por Miyazaki \& Pitelli (2003) proporcionou ótimo controle de espécies imersas, pela predação pelo pacu (Piaractus mesopotamicus). Métodos químicos também podem ser avaliados, haja vista os resultados satisfatórios e seguros de algumas espécies aquáticas imersas ou flutuantes. Neste caso específico de controle, podem ser citados estudos realizados por Marcondes et al.(2002), Tanaka et al. (2002), Martins et al. (2002), Carbonari et al. (2003) e Negrisoli et al. (2003).

Velini (2000) relata que o controle mecânico utilizando embarcações apropriadas, visando à retirada da biomassa do corpo hídrico, é uma das alternativas a serem consideradas.
A remoção (colheita) de plantas, segundo Koegel et al. (1977), é um dos métodos mais utilizados de controle mecânico, pois minimiza os problemas de reinfestação causados pelos fragmentos gerados.

Antuniassi et al. (2002) afirmam que a opção por usar métodos mecânicos ou químicos, em muitas situações, depende de análises operacionais e econômicas. O custo químico pode ser de até $10 \%$ do controle mecânico, quando são comparadas aplicações de glyphosate e uso de diferentes equipamentos.

Em contrapartida, o método mecânico apresenta algumas vantagens em relação aos demais, como ação de modo pontual nas áreas infestadas e não-contaminação do ambiente com compostos químicos e tóxicos. Apesar disso, existe a preocupação em relação à massa vegetal coletada a ser descartada, tendo em vista a grande quantidade de biomassa envolvida nesse processo.

Desse modo, o objetivo deste trabalho foi o de avaliar a decomposição de três espécies imersas problemáticas do reservatório de Jupiá (Egeria densa, Egeria najas e Ceratophyllum demersum), visando estabelecer critério de descarte seguro do material proveniente de operações de controle mecânico, bem como a melhor forma de incorporação da biomassa no solo.

\section{MATERIAL E MÉTODOS}

Anteriormente ao início do estudo de decomposição, foi realizado um ensaio, em casa de vegetação, com a finalidade de determinar o período de secagem/desidratação das plantas na superficie do solo, bem como a quantidade ideal a ser descartada em determinada área. Amostras de Egeria densa, $E$. najas e C. demersum foram homogeneizadas em proporção em peso de $1: 1: 1$, correspondente a $15,25,35$ e 50 t de matéria fresca ha ${ }^{-1}$, e dispostas como cobertura em vasos com capacidade de $14 \mathrm{~kg}$ de solo. Os tratamentos foram divididos em duas condições de solo: seco e úmido (mantido a $65 \%$ da capacidade máxima de retenção). As amostras foram pesadas diariamente, até que se atingisse a estabilidade do peso de matéria seca ao ar das plantas. 
Conforme os resultados obtidos neste ensaio, estabeleceu-se a quantidade de biomassa a ser descartada, bem como a condição de umidade ideal no solo, para que o processo de desidratação e incorporação da biomassa fosse mais bem realizado.

O estudo de decomposição de plantas aquáticas no solo foi realizado em casa de vegetação, no Núcleo de Pesquisas Avançadas em Matologia (NUPAM), da FCA/UNESP Botucatu-SP, e constituiu-se em um experimento inteiramente casualizado. De acordo com as determinações obtidas no estudo de desidratação, amostras de Egeria densa, Egeria najas e Ceratophyllum demersum, numa proporção em peso de 1:1:1, representando as quantidades de totais de 50 e $100 \mathrm{t} \mathrm{MF} \mathrm{ha}^{-1}$, foram adicionadas em vasos com capacidade de $14 \mathrm{~kg}$ de solo, apresentando área de $0,0888 \mathrm{~m}^{2}$, obedecendo-se aos períodos de desidratação natural das plantas, predeterminados no ensaio anterior.

Ao final de cada ciclo, as plantas desidratadas eram incorporadas ao solo, sendo novamente adicionadas as respectivas quantidades de plantas. Foram realizados três ciclos de desidratação e incorporação, iniciando-se a partir daí o processo de determinação de liberação de $\mathrm{CO}_{2}$, proveniente da degradação da biomassa incorporada.

Ao término do terceiro ciclo de desidratação e incorporação das plantas, o experimento foi dividido em duas partes: em uma, o solo foi irrigado $165 \%$ da capacidade máxima de retenção) e, na outra, manteve-se o solo seco, perfazendo-se assim quatro tratamentos (50 e 100 t MF ha ${ }^{-1}$, em cada condição de solo), com quatro repetições, além das testemunhas em solo seco e úmido.

Para quantificação do $\mathrm{CO}_{2}$ liberado, dentro de cada vaso foi colocado um frasco contendo $20 \mathrm{~mL}$ de solução de $\mathrm{NaOH}$ a $1 \mathrm{~N}$, para retenção do gás (Figura 1). Posteriormente, os vasos foram lacrados e incubados sob ausência de luz, a uma temperatura média de $26^{\circ} \mathrm{C}$ (Figura 2). A leitura do $\mathrm{CO}_{2}$ liberado era feita 24 horas após a incubação e, em seguida, o solo era mantido em repouso por um periodo mínimo de 48 horas.

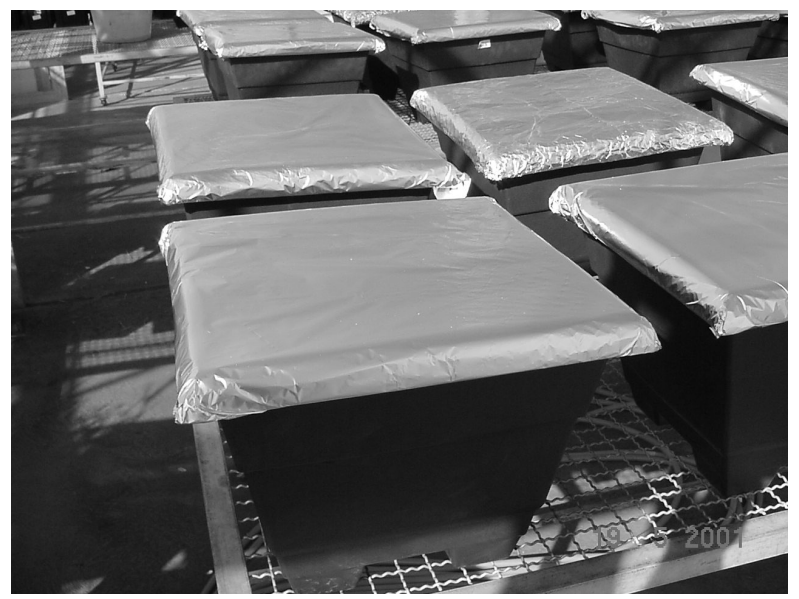

Figura 2 - Aspectos dos vasos durante o processo de incubação sob ausência de luz dos tratamentos.

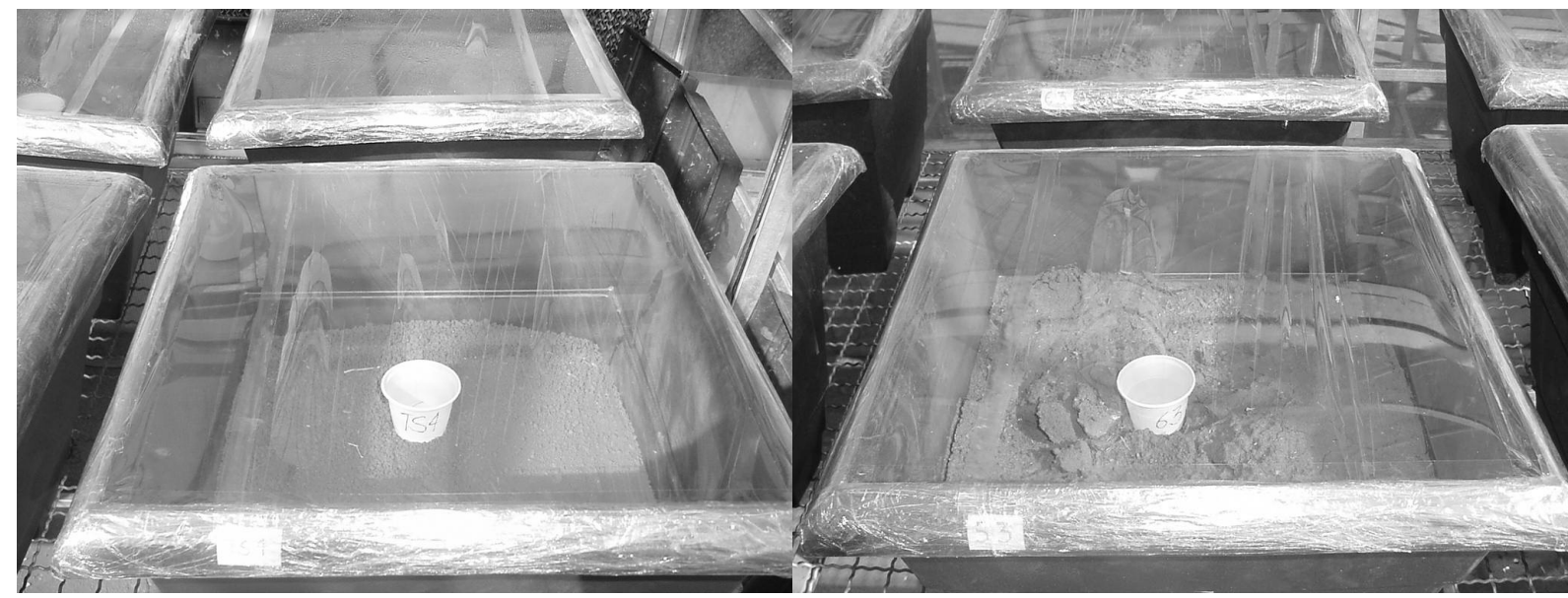

Figura 1 - Disposição dos frascos com solução durante o processo de incubação dos tratamentos. 
Após as 24 horas de incubação, os frascos contendo $\mathrm{NaOH}$ eram retirados para titulação. Inicialmente eram adicionadas a esta solução cinco gotas de solução alcoólica de fenolftaleína a $0,1 \%$, realizando-se titulação com $\mathrm{HCl}$ a $0,65 \mathrm{~N}$. Após a primeira viragem, eram adicionadas cinco gotas de solução alcoólica de di-metil-orange a 0,5\%. Quando a segunda viragem ocorria, era anotada a diferença de volume de $\mathrm{HCl}$ contido na bureta, utilizado durante as duas viragens.

A quantificação do $\mathrm{CO}_{2}$ liberado pôde ser calculada pela seguinte expressão:

$$
g \mathrm{CO}_{2} \text { liberado }=\mathrm{N}_{e q} \mathrm{CO}_{2} \times 44
$$

em que $\mathrm{N}_{e q} \mathrm{CO}_{2}=V_{\text {(titulado) }}(L) \times 0,65$.

Deve-se salientar que o valor obtido pela fórmula era demonstrado em $\mathrm{g} \mathrm{CO}_{2}$ liberado por vaso, necessitando realizar conversão para $\mathrm{kg} \mathrm{CO}$ liberado ha-1.

Os dados da titulação para quantificação de $\mathrm{CO}_{2}$ liberado no processo de respiração foram interpolados, para que pudessem ser comparados a cada dia, durante todo o período de avaliação. Estes foram analisados seguindo o modelo de Mitscherlich, a fim de que houvesse ajuste dos dados; entretanto, para que isso ocorresse, necessitou-se modificá-lo. Os modelos original e adaptado podem ser observados a seguir:

$$
\begin{aligned}
& \text { Original }-Y=A x\left(1-10^{-C x(X+B)}\right) \\
& \text { Adaptado }-Y=A x\left(1-10^{-C x X}\right)
\end{aligned}
$$

em que $Y=\mathrm{CO}_{2}$ liberado ajustado, em $\mathrm{kg} \mathrm{ha}^{-1}$; $A=$ assíntota horizontal máxima do modelo original; $C=$ concavidade da curva; e $X=\mathrm{CO}_{2}$ liberado original, em $\mathrm{kg} \mathrm{ha}^{-1}$.

\section{RESULTADOS E DISCUSSÃO}

O período médio de desidratação, em condições normais de solo seco, foi de sete dias, para todas as quantidades avaliadas (Figura 3). Portanto, com resultados obtidos neste estudo, foi estabelecida a quantidade de 50 t MF ha ${ }^{-1}$ de biomassa a ser descartada, pelo fato de não haver diferença de comportamento entre esta e as demais quantidades avaliadas. Para o estudo de decomposição, foi escolhido o equivalente ao dobro de sua quantidade, ou seja, 100 t MF ha-1. $^{-1}$

Planta Daninha, Viçosa-MG, v. 23, n. 2, p. 243-248, 2005
O estudo de decomposição da biomassa incorporada somente foi possivel no tratamento em solo seco, haja vista a dificuldade de secagem das plantas, bem como a sua incorporação em solo úmido.

A liberação de $\mathrm{CO}_{2}$ nos tratamentos testemunhas (Figura 4) mostrou-se mais intensa quando o solo estava úmido, com $444 \mathrm{~kg} \mathrm{ha}^{-1}$. Provavelmente essa liberação é proveniente do processo de decomposição da matéria orgânica já presente no solo. A liberação estudada em solo seco representou um resultado 2,3 vezes menor, indicando uma redução na velocidade de degradação das plantas no solo nessas condições.

As liberações de $\mathrm{CO}_{2}$ no solo úmido com $50 \mathrm{t} \mathrm{ha}^{-1}$ (Figura 5) e $100 \mathrm{t} \mathrm{ha}^{-1}$ (Figura 6) foram, respectivamente, 6,2 e 5,6 vezes superiores

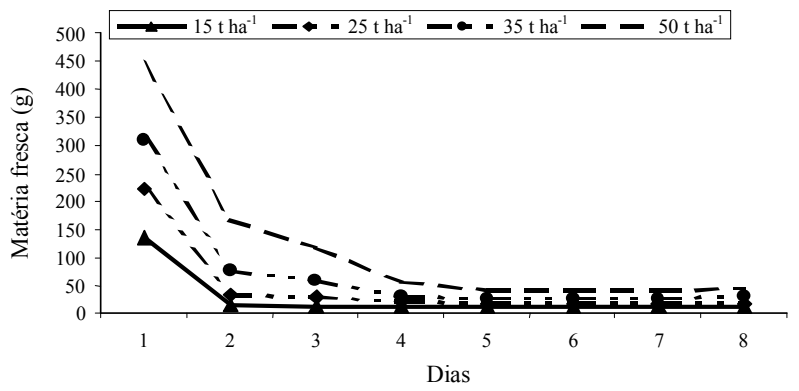

Figura 3 - Representação dos períodos de desidratação média da biomassa de plantas aquáticas em superfície de solo seco. Botucatu, 2001.

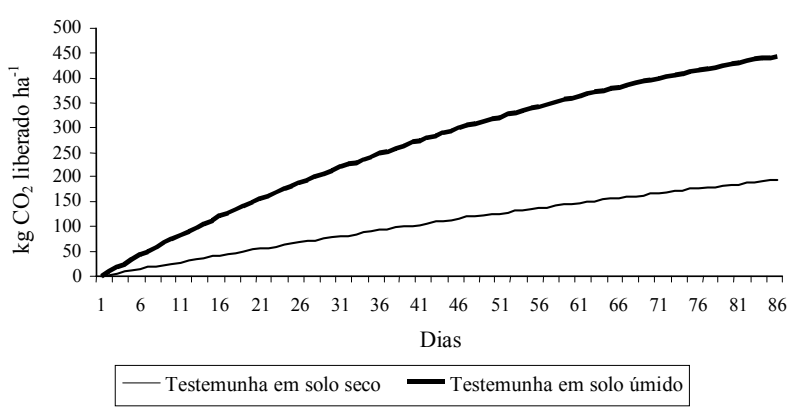

Parâmetros de Mitscherlich: Test. em solo seco $(A=480,5872$; $\left.\mathrm{C}=0,002662 ; \mathrm{R}^{2}=0,99\right)$

Test. em solo úmido $\left(A=637,71159 ; C=0,006101 ; R^{2}=0,98\right)$

Figura 4 - Liberação acumulada de $\mathrm{CO}_{2}\left(\mathrm{~kg} \mathrm{ha}^{-1}\right)$ em solo sem incorporação de plantas aquáticas durante o processo de decomposição. 
às observadas nos tratamentos correspondentes em solo seco. Em todos os tratamentos, foi observada uma maior liberação de $\mathrm{CO}_{2}$ durante os primeiros 30 dias, com liberação média de $55 \%$ do carbono total para os tratamentos em solo úmido. Em parte, esse comportamento pode ser devido à movimentação do solo dos vasos, associado à incorporação de água juntamente com o material vegetal.

Machado et al. (1999), trabalhando com liberação de $\mathrm{CO}_{2}$ em solo incorporado com poaiabranca (Richardia brasiliensis), observaram liberação de carbono na ordem de $77 \%$, especialmente nos dez dias iniciais de incubação. Valores próximos a este também foram observados por Fellerhoff et al. (2003) para decomposição de Nymphaea amazonum, nos primeiros

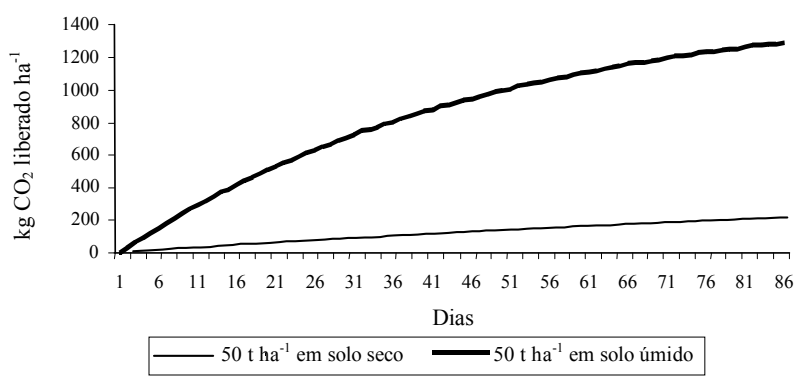

Parâmetros de Mitscherlich: 50 t em solo seco (A=327,27633; $\left.\mathrm{C}=0,005155 ; \mathrm{R}^{2}=0,98\right)$

50 t em solo úmido $\left(A=1557,48444 ; C=0,009086 ; R^{2}=0,99\right)$

Figura 5 - Liberação acumulada de $\mathrm{CO}_{2}\left(\mathrm{~kg} \mathrm{ha}^{-1}\right)$ em solo com incorporação de $50 \mathrm{t} \mathrm{MF} \mathrm{ha-1}$ de plantas aquáticas durante o processo de decomposição.

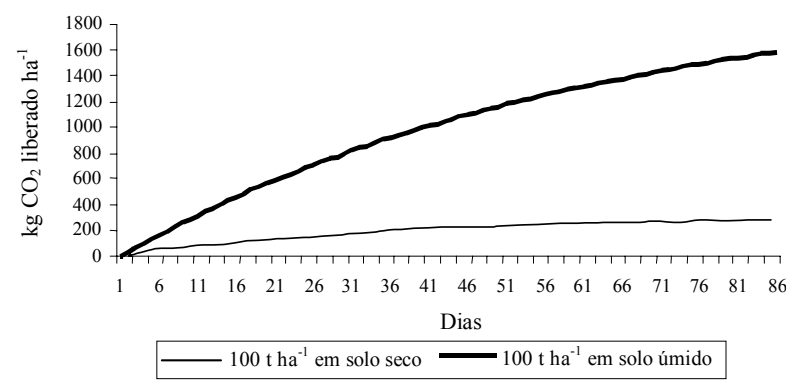

Parâmetros de Mitscherlich: 100 t em solo seco (A=298,97047; $\left.\mathrm{C}=0,014236 ; \mathrm{R}^{2}=0,97\right)$

100 t em solo úmido $\left(A=2096,40183 ; C=0,00718 ; R^{2}=0,99\right)$

Figura 6 - Liberação acumulada de $\mathrm{CO}_{2}\left(\mathrm{~kg} \mathrm{ha}^{-1}\right)$ em solo com incorporação de $100 \mathrm{t} \mathrm{MF} \mathrm{ha}^{-1}$ de plantas aquáticas durante o processo de decomposição. dez dias de estudo. Ao contrário, Minhoni et al. (1990) observaram valores inferiores quando testaram esse efeito degradativo em solo com adição de vinhaça e bagaço de cana.

Após esse período inicial, nota-se, nos tratamentos em solo seco, equilíbrio e estabilização do processo de liberação de $\mathrm{CO}_{2}$, acarretando diminuição do processo degradativo da biomassa incorporada. Entretanto, o mesmo não foi observado em solo úmido, onde há aumento progressivo da liberação de $\mathrm{CO}_{2}$ e, conseqüentemente, do processo de decomposição da matéria seca incorporada ao solo.

Dessa forma, o processo de degradação da biomassa incorporada no solo passa a ser um tanto longo, até que se estabilize em níveis normais. Esse fato pode determinar um intervalo seguro entre descartes, fazendo com que se saiba em quanto tempo o material irá ser decomposto para que um novo descarte possa ser realizado.

Pelo estudo de respiração microbiana, através da liberação de $\mathrm{CO}_{2}$, nota-se que o solo, quando em condição de umidade, favorece prontamente a decomposição da biomassa incorporada, com índices superiores a $75 \%$ quando comparados à decomposição em solo seco. Esse fato pôde ser comprovado por estudos realizados por Machado et al. (1999) e Fellerhoff et al. (2003), os quais também observaram essa tendência no processo de decomposição de algumas espécies de macrófitas aquáticas.

O estudo permitiu observar que o descarte da biomassa de macrófitas aquáticas, realizado em solo seco, é a melhor alternativa para secagem/desidratação e incorporação desta, mesmo em grandes quantidades. No entanto, a existência de um sistema de irrigação, para que o processo de degradação da biomassa incorporada seja acelerado, também deve ser considerada.

\section{LITERATURA CITADA}

ANTUNIASSI, U. R.; VELINI, E. D.; MARTINS, D. Remoção mecânica de plantas aquáticas: avaliação econômica e operacional. Planta Daninha, v. 20, p. 35-43, 2002. (Edição especial)

ASAEDA, T.; TRUNG, V. K.; MANTUNGE, J. Modeling the effects of macrophyte growth and decomposition on the nutrient budget in Shallow Lakes. Aquatic Bot., v. 68, p. $217-237,2000$.

Planta Daninha, Viçosa-MG, v. 23, n. 2, p. 243-248, 2005 
BRAGA, M. F. S. Estudo de recifes artificiais como atratores de peixes no reservatório de Volta Grande, Rio Grande (MGSP). Acta Limn. Bras., v. 14, n. 2, p. 65-76, 2002.

FELLERHOFF, C.; VOSS, M.; WANTEN, K. M. Stable carbon and nitrogen isotope signatures of decomposing tropical macrophytes. Aquat. Ecol., v. 37, p. 361-375, 2003.

CARBONARI, C. A.; MARTINS, D.; TERRA, M. A. Controle de Brachiaria subquadripara e Brachiaria mutica através de diferentes herbicidas aplicados em pósemergência. Planta Daninha, v. 21, p. 79-84, 2003. (Edição especial)

KOEGEL, R. G.; LIVERMORE, D. F.; BRUHN, H. D. Costs and productivity in harvesting of aquatic plants. J. Aquat. Plant Manag., v. 15, p. 12-17, 1977.

MACHADO, E. S.; MINHONI, M. T. A.; BÜLL, L. T. Liberação de $\mathrm{CO}_{2}$, biomassa microbiana e fósforo disponível em solo adicionado de matéria seca de poaia-branca. Planta Daninha, v. 17, n. 1, p. 73-81, 1999.

MARCONDES, D. A. S. et al. Eficiência do fluridone no controle de plantas aquáticas submersas sobre algumas características ambientais. Planta Daninha, v. 20, p. 63-71, 2002. (Edição especial)

MARTINS, D. et al. Controle químico de Pistia stratiotes, Eichhornia crassipes e Salvinia molesta. Planta Daninha, v. 20, p. 83-88, 2002.
MIYAZAKI, D. M. Y.; PITELLI, R. A. Estudo do potencial do pacu (Piaractus mesopotamicus) como agente de controle biológico de Egeria densa, E. najas e Ceratophyllum demersum. Planta Daninha, v. 21, p. 53-59, 2003. (Edição especial)

MINHONI, M. T. A.; EIRA, A. F.; CARDOSO, E. J. B. N. Efeitos da adição de $\mathrm{N}$ e $\mathrm{P}$ sobre a decomposição de diferentes tipos de material orgânico no solo. R. Bras. Ci. Solo, v. 14, p. 297-304, 1990.

NEGRISOLI, E. et al. Uso de diferentes herbicidas no controle de Myriophyllum aquaticum. Planta Daninha, v. 21, p. 89-92, 2003. (Edição especial)

TANAKA, R. H. et al. Avaliação de herbicidas para o controle de egéria em laboratório, caixa d'água e represa sem fluxo de água. Planta Daninha, v. 20, p. 73-81, 2002. (Edição especial)

THOMAZ, S. M.; BINI, L. M. Ecologia e manejo de macrófitas aquáticas em reservatórios. Acta Limn. Bras., v. 10, n. 1, p. 103-116, 1998.

VELINI, E. D. Controle de plantas daninhas aquáticas. In: CONGRESSO BRASILEIRO DA CIÊNCIA DAS PLANTAS DANINHAS, 22., 2000, Foz do Iguaçu. Palestras... Foz do Iguaçu: SBCPD, 2000. p. 137-147. 